\title{
NANOMETER-SCALE MECHANICAL PROPERTIES OF MWCNT-MUSTARD OIL NANOFLUID AS A POTENTIAL BASE STOKE
}

\author{
V. VIGNESH ${ }^{a^{*}}$, S. VIJAYAN ${ }^{b}$ AND G. SELVAKUMAR ${ }^{c}$ \\ ${ }^{a}$ Assistant Professor, Department of Mechanical Engineering, St. Mother Theresa Engineering College, Vagaikulam-628103, Fax: +914622501007.
${ }^{b}$ Associate Professor, Department of Mechanical Engineering, Sri Sivasubramaniya Nadar College of Engineering, kalavakkam, Chennai 603110. \\ ${ }^{c}$ Associate Professor, Department of Mechanical Engineering, Sri Sivasubramaniya Nadar College of Engineering, kalavakkam, Chennai 603110.
}

\begin{abstract}
Nowadays, environmentally friendly lubricants are developed to meet the standards of biodegradability, toxicity and bioaccumulation potential that reduce the adverse consequences to the aquatic atmosphere compared to conventional mineral based lubricants. In this study, an attempt made to enhance the feasibility of utilizing the Mustard oil as a commercial lubricating agent by homogeneously dispersing MWCNTs as an additive. The average crystallite size, surface morphology and elements of MWCNT are characterized through XRD, SEM, EDS and FTIR techniques, respectively. The surface deformation rate of matrix material (Mg) lubricated by Mustard oil and different weight fractions of MWCNT-Mustard oil nanofluid are estimated through Nanoindentation technique. The hardness, Young's modulus and AFM topography of the interacting surface infers that the dispersed MWCNT significantly enhance the lubricating properties of Mustard oil through micro-chipping and micro-softening effect.
\end{abstract}

Keywords: Biodegradability; mustard oil; nanoindentation; micro-chipping; micro-softening; lubricating properties.

\section{INTRODUCTION}

The increasing price, poor biodegradability and worldwide large-scale necessity of conventional mineral based lubricants forced the developers to formulate Environmentally Acceptable Lubricating agents (EAL) from agricultural feed stocks according to new global environmental regulations [1]. EAL lubricants are biodegradable and renewable vegetable oils $(75-80 \%)$ that are favored over mineral based lubricant oil as base stock and their main component is triglycerides. The remaining fraction of EAL consists of performance enhancing nano-scaled additives [2]. The characteristic issues of bio oils are thermo-oxidative instability and poor cold flow behavior. To diminish the ecological damage caused by mineral lubrication oils, it is essential to enhance the distinctiveness of bio oils to compete with mineral oils commercially. The chemico-physical distinctiveness of the bio-oils is highly influenced by temperature and their fatty acid compositions [3]. The recent research evolutions have exposed a promise to conquer these infirmities through dispersing performance enhancing nano-scaled additives [4] and blending by other mineral based oils [2].

The nanofluids like $\mathrm{Al}_{2} \mathrm{O}_{3}$-Vegetable oil [5], $\mathrm{Al}_{2} \mathrm{O}_{3}$-Pure coconut oil [6], $\mathrm{MoS}_{2}$ Diesel oil [7], ZnO-Rice bran oil, ZnZrO-Rice bran oil [8], MWCNT-Sunflower oil [9], $\mathrm{TiO}_{2}$-Compressor oil [10], $\mathrm{ZnO}$-Paraffin oil [11], $\mathrm{Fe}_{3} \mathrm{O}_{4}$-Hydraulic oil [12], Goethite nanofluids [13], $\mathrm{SiO}_{2}$-Polyalkylene glycol nanofluids [14], $\mathrm{SiO}_{2}$ Cutting Fluids [15], CuO-Base oil [16], Magnetic-nanofluids [17], $\mathrm{Al}_{2} \mathrm{O}_{3}$ Therminol 55 [18], Magneto-hydrodynamic (MHD) nanofluids [19], hybrid nanofluids [20], Graphene oxide-Ethylene glycol [21], $\mathrm{SiO}_{2}$-Glycerol [22], $\mathrm{TiO}_{2}-$ Water, $\mathrm{SiO}_{2}$-Water [23], $\mathrm{Au}, \mathrm{Au} / \mathrm{Pt}, \mathrm{Au} / \mathrm{Pt} / \mathrm{Ag}$ nanofluid [24], $\mathrm{Al}_{2} \mathrm{O}_{3}-$ Water, CuO-Water [25], CNT-Water [26], ZnO-Water [27], Ag-Water [28], GarnetGear lubricant [29-30], NiO-nanofluids [31], CaO-Nanofluids [32] etc. have extensively augmented the chemico-physical distinctiveness over their base fluid such as electrical conductivity, pressure drop, friction factor, heat transfer coefficient and fouling thermal resistance and tribological parameters [5-32].

Among the wide range of bio-oils, the Mustard oil has a distinctive pungent taste which is often used for cooking in North India, Nepal, Bangladesh and Pakistan. The pungency of mustard oil is due to the presence of allyl isothiocyanate, an activator of the TRPA1 channel (Transient receptor potential cation channel, subfamily A) in sensory neurons. The viscosity index of Mustard oil is 205 [33] where as SAE20W40 lubricant [34], Sunflower oil [35], Rapeseed oil [36], Jatropha oil [37], Rice bran oil [38], Rubber seed oil [39], Palm oil [40], Millettia Pinnata oil [41], Coconut oil [42] has the viscosity index of 142, 176, $180,205,169,182,186,169,159$, respectively. Generally, the Mustard oil has the average thermal conductivity of $0.166-0.171 \mathrm{~W} / \mathrm{mK}$ at $20^{\circ} \mathrm{C}, 0.169-174$ $\mathrm{W} / \mathrm{mK}$ at $60^{\circ} \mathrm{C}$ and the average dynamic viscosity of $93.9 \mathrm{mPa} . \mathrm{s}$ at $20^{\circ} \mathrm{C}, 20.989$ $\mathrm{mPa} . \mathrm{s}$ at $60^{\circ} \mathrm{C}$ [43]. The coconut oil exhibits high wear rate and pour point compared to mineral oils [44]. The chemico-physical and thermo-physical distinctiveness and of rice bran oil are significantly higher than other vegetable oils and SAE20W40 (commercial lubricant mineral oil) [38]. However, the Mustard oil exposed superior wear resistance than coconut oil [44]. The chemicophysical and thermo-physical distinctiveness of the Mustard oil may be enhanced by homogeneously dispersing the carbon nanotubes (CNT).

The carbon nanotubes such as single-wall carbon nanotubes (SWCNT) and multi-wall carbon nanotubes (MWCNT) are the long straight and parallel carbon layers of cylindrically rolled bulky tubes that received a great consideration since their development due to admirable gas sensing [45], thermal [46], electrical [47], mechanical [48] and tribological [49] distinctiveness. They also widely applied as carriers in therapeutic/detective molecules [50], energy storage [51], electrodes, sensors [52] and nuclear waste management [53]. The MWCNTs can be dispersed into the any base fluid medium through the mechanical agitation methods like ultrasonication technique and the diverse concentrations of MWCNT- Mustard oil nanofluids shall be formulated [33-36]. The surface deformation behavior of lubricated matrix materials (Magnesium) shall be quantitatively investigated through the nanoindentation technique [54-55]. The Magnesium is utilized as a matrix material as it is a class of biodegradable metals having enormous possibility to be used as implant materials [56].

In this study, an experimental investigation on the use of wild Mustard oil based nanofluid as lubrication oil for the matrix material by nano-indentation technique is reported.

\section{MATERIALS AND METHODS}

\subsection{Materials}

The brown Indian mustard (Brassica juncea) seeds (average diameter is 1476 $\mathrm{mm}$ ) are cold pressed and Mustard oil is extracted through traditional Oxpowered mill grinding followed by filtration without adding any preservatives. It has high levels of alpha-linolenic and erucic acid in nature [57]. The MWCNT is homogeneously suspended into the raw Mustard oil using ultrasonication technique and different weight fractions $(0.2 \mathrm{wt} \%$ and $0.4 \mathrm{wt} \%)$ of MWCNTMustard oil nanofluid are formulated. The MWCNT used in this study is purchased from PlasmaChem $\mathrm{GmbH}$, Germany and their physical properties as given by the producer are given in the Table 1 . 
Table 1 Physical properties of MWCNT

\begin{tabular}{|l|l|}
\hline Number of walls & $3-15$ \\
\hline Specific surface area & $238 \mathrm{~m}^{2} / \mathrm{g}$ \\
\hline Outer diameter & $80-140 \mathrm{~nm}$ \\
\hline Inner diameter & $2-6 \mathrm{~nm}$ \\
\hline Length & $1-10 \mu \mathrm{m}$ \\
\hline Purity (Carbon) & $>95 \%$ \\
\hline Apparent density & $200 \mathrm{~g} / \mathrm{cm}^{3}$ \\
\hline
\end{tabular}

\subsection{Methods}

The average crystallite size of MWCNTs is estimated through X-ray powder diffraction (XRD) and their elements are confirmed by Energy Dispersive X-Ray Spectroscopy (EDS). The surface morphology is investigated by Scanning Electron Microscopy (SEM) and the molecular fingerprint of MWCNT is investigated through Fourier Transform Infrared Spectroscopy (FTIR).

The surface deformation rate of matrix material lubricated by Mustard oil and different weight fractions of MWCNT-Mustard oil nanofluid are estimated through Nanoindentation technique. The surface deformation level under the action of external force is depends on the physical properties of matrix material and their mode of lubrication. A polished magnesium $(\mathrm{Mg})$ specimen of size $(10 \times 10 \times 10) \mathrm{mm}$ is used as a matrix material. The elastic, visco-elastic and plastic distinctiveness of matrix material like hardness, strain-rate, elasticity, contact stiffness and plasticity index are determined through the continuous stiffness measurements. This method is mainly concerned with the depth of penetration to nanometer $(\mathrm{nm})$ resolution and the measuring the forces in the micronewton $(\mu \mathrm{N})$ range in high accuracy and precision. The trapezoidal quasi-static loaddisplacement curve of Nanoindentation study exposes the ability to resist the surface deformation through the continuous evaluation of the hardness and Young's modulus of the lubricated/non-lubricated matrix material over the depth of the indentation. The surface deformation level of matrix material is observed by lubricating Mustard oil and different weight fractions of MWCNT-Mustard oil nanofluid.

\section{RESULTS AND DISCUSSION}

The XRD pattern of the pristine MWCNT is presented in the Figure 1. The characteristic sharp diffraction peak centered at $(2 \Theta) 25.5^{\circ}, 42.9^{\circ}, 53.2^{\circ}$ respectively is due to diffraction of from the (002), (110) and (004) planes of MWCNT which authenticate the graphitic nature of CNT [58]. The interlayer spacing between the inner tubes of MWCNT estimated from the XRD peak of (002) plane using the equation $d_{002}=0.345+0.37 e^{-D / 14.4}$ is in the range of $0.333-0.337 \mathrm{~nm}$. The average crystallite size of MWCNT estimated through Debye-Scherrer correlation [59] is $26.715 \mathrm{~nm}$. The EDS spectrum of MWCNT presented in the Figure 2 illustrates the characteristic Carbon band and confirms the existence of MWCNT.

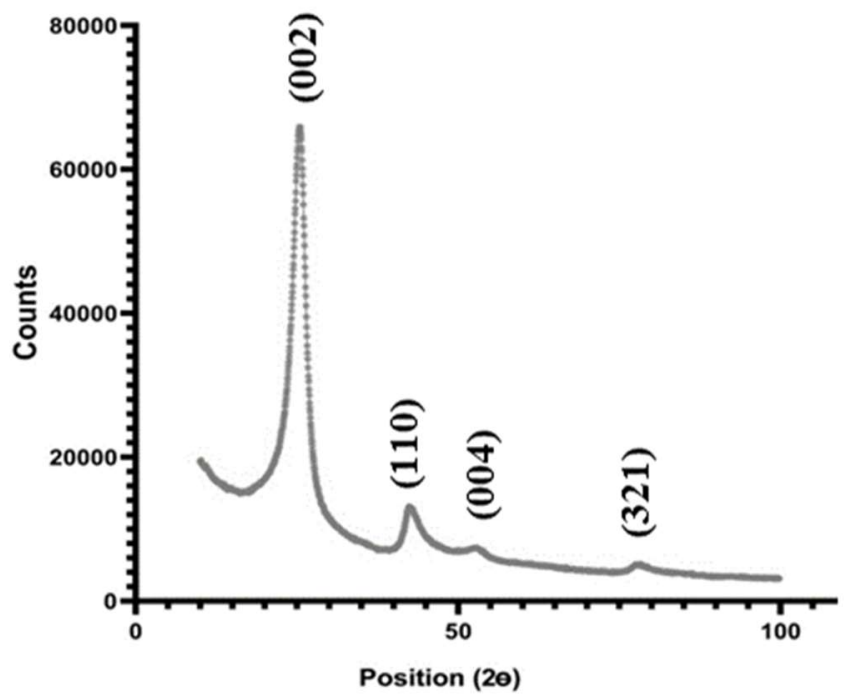

Figure 1. XRD pattern of MWCNT

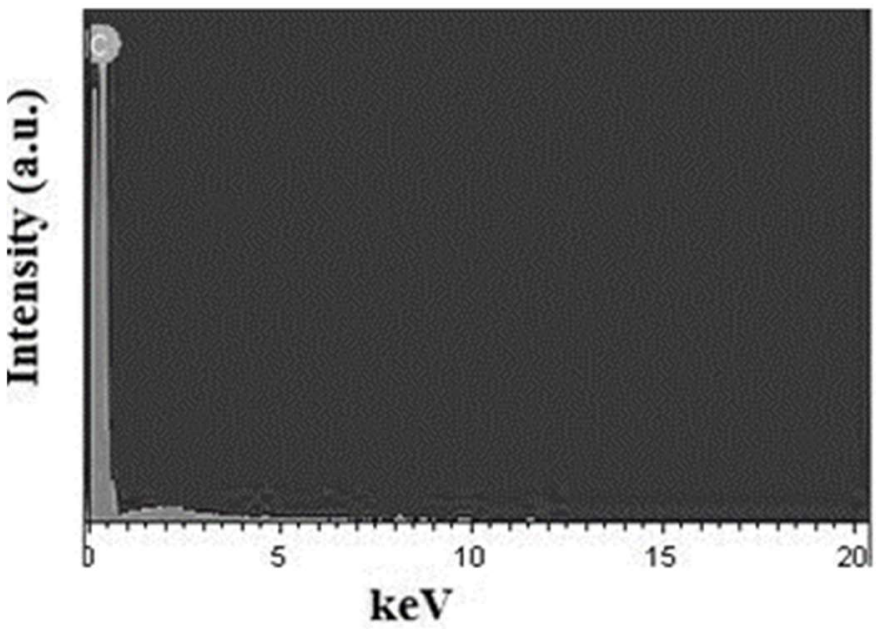

Figure 2. EDS spectrum of MWCNT

The surface morphology of MWCNT investigated by SEM and represented in the Figure 3. It manifestly exhibit that the MWCNTs are densely packed and are randomly aligned intermingled ropes with the average outer diameter is ranging from 80 to $140 \mathrm{~nm}$ with few micrometers length. The agglomeration of MWCNTs is not observed and the tube-walls appear smooth. However, it may tend to restack due to van der Waals attractive forces and strong molecular interactions. In general, it has low density, high specific surface area and large aspect ratio compared to other nanomaterials. The structure of MWCNT has regular hexagonal lattice on the cylindrical plane.

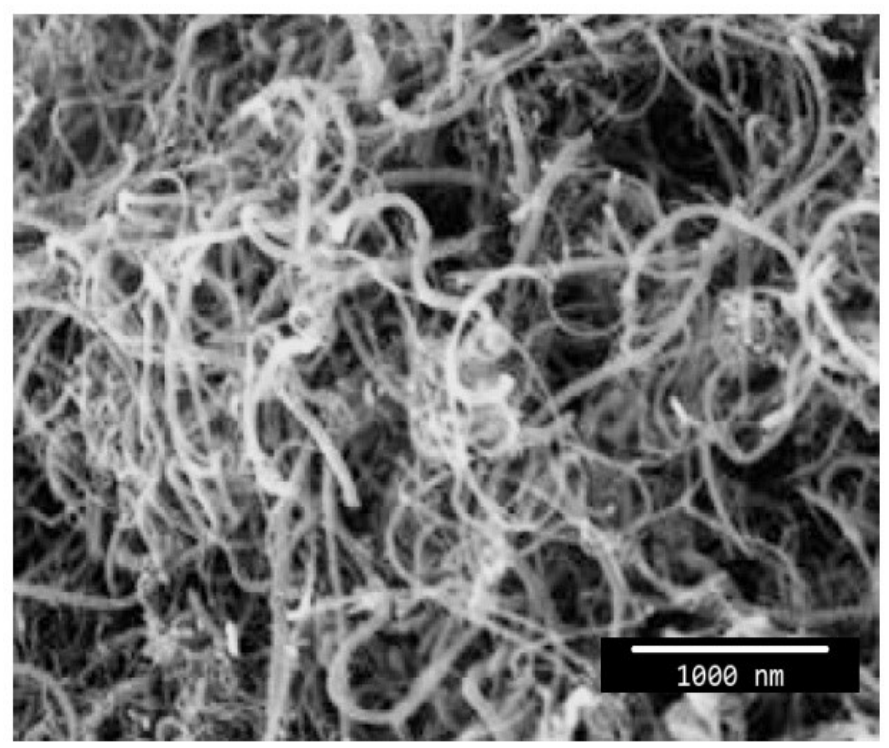

Figure 3. The surface morphology of MWCNT (SEM image)

The FTIR spectra of MWCNT are presented in the Figure 4 is obtained in the transmission mode at the range of $500-4000 \mathrm{~cm}^{-1}$ at room temperature. The intense peak found at $2404 \mathrm{~cm}^{-1}$ is ascribed to the asymetric stretching $\mathrm{CO}_{2}$. The vibrational frequencies at $2367 \mathrm{~cm}^{-1}$ and $2361 \mathrm{~cm}^{-1}$ are due to the stretching vibration of $\mathrm{C}-\mathrm{O}$ bonds. The stretching $\mathrm{C}=\mathrm{O}$ vibration of the carboxyl $(\mathrm{COOH})$ group is observed at $1722 \mathrm{~cm}^{-1}$. The intense peak approximately at $1700 \mathrm{~cm}^{-1}$ represent the $\mathrm{C}=\mathrm{O}$ stretching vibration mode. The strong absorption band at 1687 $\mathrm{cm}^{-1}$ represents the acid carbonyl $(\mathrm{C}=\mathrm{O})$ stretches. The peak observed at around $1640 \mathrm{~cm}^{-1}$ represents the $\mathrm{C}=\mathrm{C}$ asymmetric stretching vibrations and the peak found at $1030 \mathrm{~cm}^{-1}$ is assigned to $\mathrm{C}-\mathrm{H}$ in plane bending. The band found approximately at $1636 \mathrm{~cm}^{-1}$ is due to the stretching $\mathrm{C}=\mathrm{C}$ bonds. The peak appeared at $1533 \mathrm{~cm}^{-1}$ ascribed to the bending vibration of carbonyl group. The bands appeared between $1448 \mathrm{~cm}^{-1}$ to $1636 \mathrm{~cm}^{-1}$ represents the $\mathrm{C}=\mathrm{C}$ symmetric stretching vibrations of MWCNT and the bands appeared between $1050 \mathrm{~cm}^{-1}$ to $1390 \mathrm{~cm}^{-1}$ are assigned to C-O symmetric stretching vibrations. 


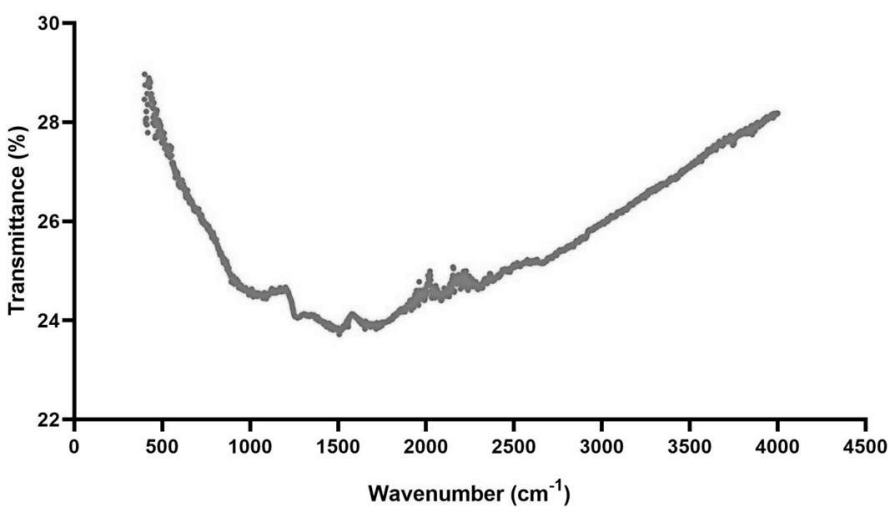

Figure 4. FTIR spectra of MWCNT

The Nanoindentation investigation is carried out by applying $6000 \mu \mathrm{N}$ normal load in a closed room atmosphere $\left(24^{\circ} \mathrm{C}\right.$ and $38 \%$ relative humidity) using standard Berkovich indenter and their characteristic Force-displacement profile consists loading, holding and unloading cycles. The Force-displacement profile is plotted and investigated for estimating the surface roughness parameters. The Force-displacement profile of $\mathrm{Mg}$ alloy at $6000 \mu \mathrm{N}$ normal load is illustrated in Figure 5.

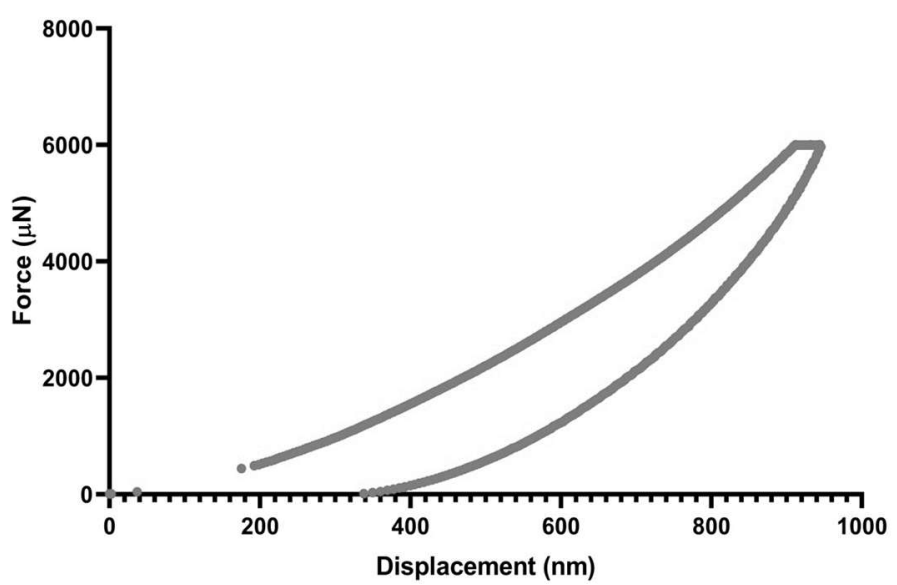

Figure 5. Force-displacement profile of $\mathrm{Mg}$ alloy at $6000 \mu \mathrm{N}$ load.

In general, Magnesium is $33 \%$ lighter than aluminum, $60 \%$ lighter than titanium, $75 \%$ lighter than steel and has two-thirds the density of aluminium also it reacts with atmosphere at room temperature. The polycrystalline $\mathrm{Mg}$ has brittle nature and easily fractures along shear bands. The matrix material exhibited relatively vertiginous Force-displacement profile from the beginning to the end of the loading profile. Once the indentation on the $\mathrm{Mg}$ matrix material is started, a sudden prelude on the Force-displacement profile is perceived till $400 \mu \mathrm{N}$ normal load where the indenter penetrated for $185 \mathrm{~nm}$ due to brittle fracture. Further, the indentation depth successively increases for the given peak load without any pop-in event which results constant elastic-plastic surface deformation till the end of loading. At the end of the loading segment, the peak load is retained at $6000 \mu \mathrm{N}$ for $10 \mathrm{~s}$ for experiencing creep where $52 \mathrm{~nm}$ creepdisplacements is recorded with the plastic dislocations such as slip and climb at the interacting surface. The unloading profile is then obtained where the applied load is brought to zero in $10 \mathrm{~s}$.

The initial unloading profile is quite elastic in nature and the indentation modulus of the matrix material is inferred from the initial slope of the unloading profile. The indentation modulus and hardness of matrix material estimated from the unloading curve are $4.78 \mathrm{GPa}$ and $458.09 \mathrm{MPa}$, respectively. The contact stiffness of the matrix material estimated by fitting a straight line to the upper about one third portion of the unloading curve from the peak load is $19.5 \mu \mathrm{N} / \mathrm{nm}$. The adhesion between the Berkovich indenter and matrix material observed at the end of unloading profile. Further, the interacting surface of the matrix material is drop lubricated by raw Mustard oil and their Force-displacement profile at $6000 \mu \mathrm{N}$ normal load is illustrated in Figure 6.

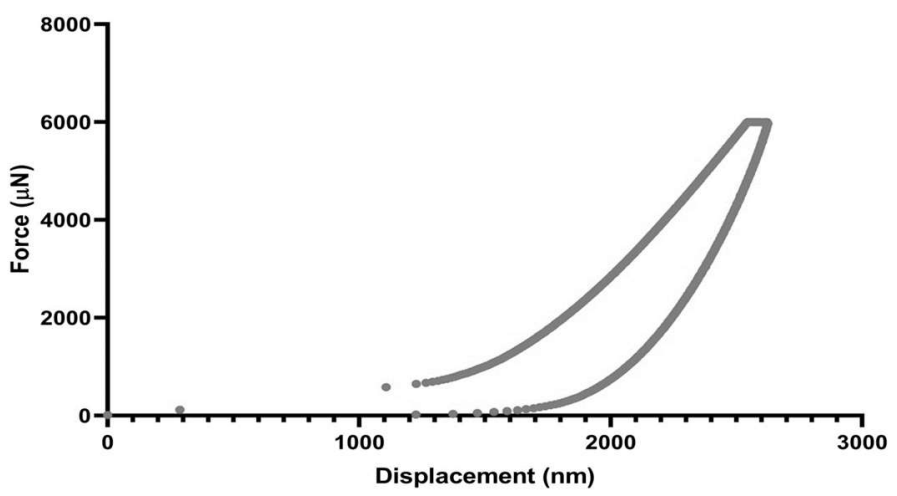

Figure 6. Force-displacement profile of matrix material lubricated by raw Mustard oil.

The loading and unloading curve (Figure 6) obtained from the drop lubrication of matrix material by raw Mustard oil is apparently differs from that of non lubricated matrix material. In the Force-displacement profile of matrix material lubricated by raw Mustard oil also has a sudden prelude displacement till $900 \mu \mathrm{N}$ normal load where the indenter penetrated approximately for $1310 \mathrm{~nm}$ due to brittle fracture. Further, the indentation depth successively increases for the given peak load without any pop-in event which results constant elastic-plastic surface deformation till the end of loading profile. At the end of the loading segment 42 $\mathrm{nm}$ creep-displacement is recorded with the plastic surface deformations. The indentation modulus, hardness and contact stiffness of matrix material estimated from the unloading curve are $5.42 \mathrm{GPa}, 233.64 \mathrm{MPa}$ and $29.9 \mu \mathrm{N} / \mathrm{nm}$, respectively. A slight adhesion between the Berkovich indenter tip and matrix material observed at the end of unloading profile. Further, the interacting surface of the matrix material is lubricated by $0.2 \mathrm{wt} \%$ and $0.40 \mathrm{wt} \%$ of MWCNTMustard oil nanofluid and their Force-displacement profile are illustrated in the Figure 7 and Figure 8, respectively.

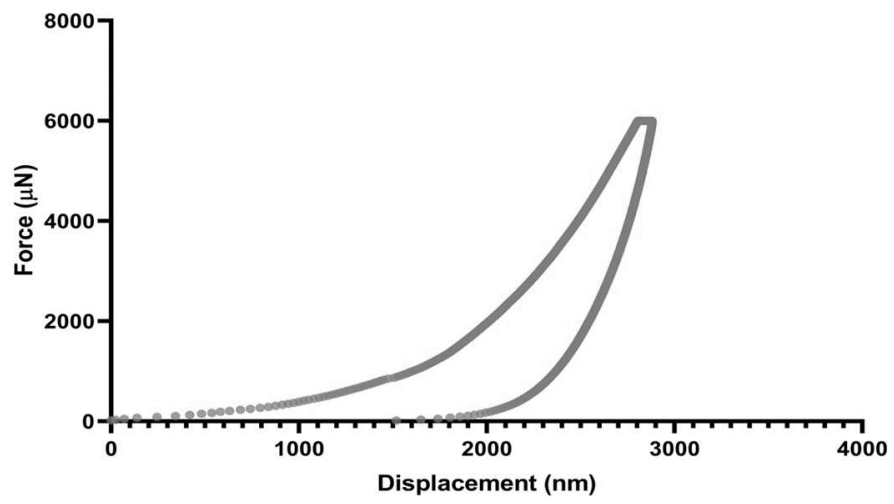

Figure 7. Force-displacement profile of matrix material lubricated by $0.2 \mathrm{wt} \%$ of MWCNT-Mustard oil nanofluid.

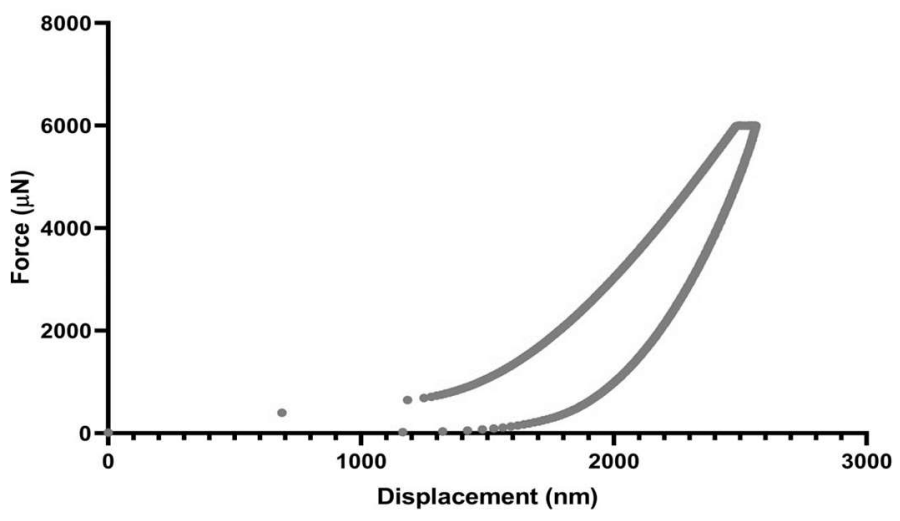

Figure 8. Force-displacement profile of matrix material lubricated by $0.4 \mathrm{wt} \%$ of MWCNT-Mustard oil nanofluid. 
The loading and unloading curve of the Force-displacement profile obtained from the lubrication of matrix material by $0.2 \mathrm{wt} \%$ and $0.4 \mathrm{wt} \%$ of MWCNTMustard oil nanofluid are obviously differs from that of matrix material and matrix material lubricated by raw Mustard oil. It disseminates that the deformation scales of the interacting surface of lubricated matrix material differs from non-lubricated matrix material. The permanent plastic deformation of matrix material begins from $800 \mu \mathrm{N}$ normal load whereas the $0.2 \mathrm{wt} \%$ MWCNTMustard oil nanofluid lubricated matrix material plastically deforms approximately after $1000 \mu \mathrm{N}$ normal load and the same is indicated through a pop-in event (Figure 7). It is the critical transition load which elucidates the nucleation of instantaneous micro and nano scale twinning as well as cracking due to the relative motion between Berkovich indenter-nanofluid-matrix materials under mechanical stress. However, any pop-in event is not found in the unloading profile.

The Force-displacement profile of the matrix material lubricated by $0.4 \mathrm{wt} \%$ of MWCNT-Mustard oil nanofluid illustrated in the Figure 8 demonstrates that the matrix material plastically deforms approximately after $1133 \mu \mathrm{N}$ normal load which is observed through the swift steep response. The displacement further increases with increase in the normal load with instantaneous surface modification of the interacting surface till the end of loading profile. Although the unloading profile of all specimens appears similar, the Force-displacement profile of matrix material lubricated by raw Mustard oil and $0.2 \mathrm{wt} \%$ of MWCNT-Mustard oil nanofluid lubricated matrix material has extensive adhesive profile. Nevertheless, the nanofluid lubricated matrix material produced maximum displacement as the dispersed MWCNT constricted between the Berkovich indenter and interacting surface makes successive stress inducedphase transformation as well as point deformations. The $0.2 \mathrm{wt} \%$ and $0.4 \mathrm{wt} \%$ of MWCNT-Mustard oil nanofluid lubricated matrix material has $1.03 \mathrm{GPa}$ and 1.06 GPa of indentation modulus; $35.98 \mathrm{MPa}$ and $48.85 \mathrm{MPa}$ of hardness and 15 $\mu \mathrm{N} / \mathrm{nm}$ and $13.2 \mu \mathrm{N} / \mathrm{nm}$ of contact stiffness, respectively. It infers that a thin layer of nanofluid absorbed the indentation pressure supplied by the Berkovich indenter and divides it throughout the interacting surface and develops softening effect. The quantitative determination of surface roughness parameters of the matrix material lubricated by $0.2 \mathrm{wt} \%$ and $0.4 \mathrm{wt} \%$ of MWCNT-Mustard oil nanofluid are studied by the in-situ AFM topography observations to extract the surface roughness values and portrayed in the Figure 9 and Figure 10, respectively.

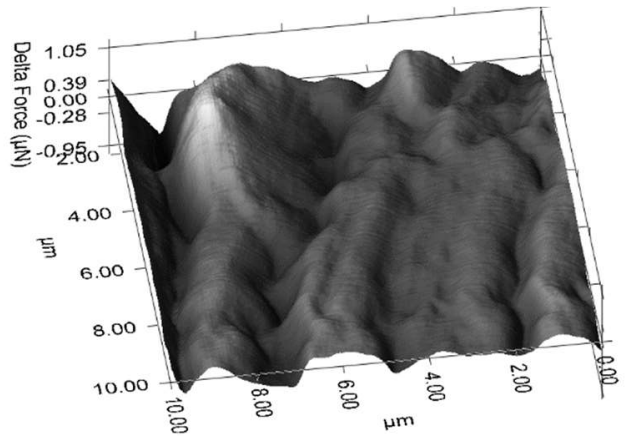

Figure 9. AFM of matrix material lubricated by $0.2 \mathrm{wt} \%$ of MWCNT-Mustard oil nanofluid.

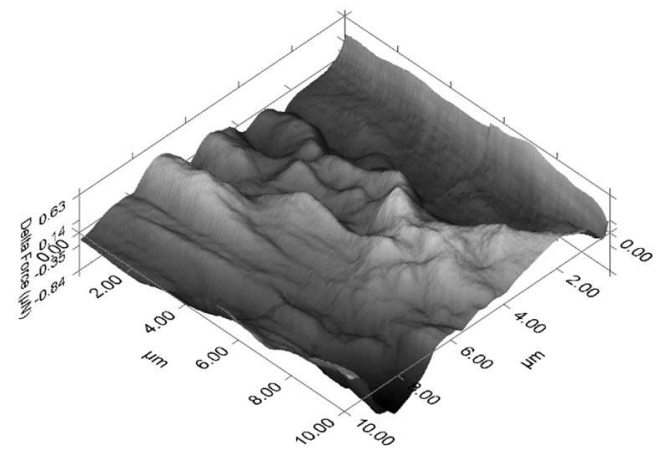

Figure 10. AFM of matrix material lubricated by $0.4 \mathrm{wt} \%$ of MWCNTMustard oil nanofluid.
The worn surface topology of reveals that the matrix material, Mustard oil lubricated matrix material, and matrix material lubricated by $0.2 \mathrm{wt} \%$ as well as $0.4 \mathrm{wt} \%$ of MWCNT-Mustard oil nanofluid developed $0.342,0.245,0.174$ \& $0.2527 \mu \mathrm{N}$ of root mean square value; $0.2506,0.178,0.1135 \& 0.196 \mu \mathrm{m}$ of average interacting surface roughness; $0.39,0.0324,0.055 \& 0.051 \mu \mathrm{m}$ of mean height; $1.556,1.053,0.3802 \& 0.673 \mu \mathrm{m}$ of maximum height, respectively. It show that the nanofluids lubrication have significantly contributed in the surface softening effect under stress induced-phase transformations. The high level of the average roughness of interacting surface and root mean square value unequivocally exposes that the dispersion of MWCNT into Mustard oil has significantly contributes in the enhancement of surface roughness parameters. The Figure 9 show that the surface topography of matrix material lubricated by $0.2 \mathrm{wt} \%$ of MWCNT-Mustard oil nanofluid has minimum height of micro-plastic twinning and slip bands than the matrix material lubricated by $0.4 \mathrm{wt} \%$ of MWCNT-Mustard oil nanofluid shown in Figure 10 for the unaltered loading conditions. The peak to valley interspaces of the matrix material, Mustard oil lubricated matrix material, and matrix material lubricated by $0.2 \mathrm{wt} \%$ as well as $0.4 \mathrm{wt} \%$ of MWCNT-Mustard oil nanofluid are 3.42, 2.0058, $1.044 \& 1.484 \mu \mathrm{m}$, respectively. In this way, the AFM outcome of surface roughness obtained from dissimilar locations exhibits noteworthy variation. Further, the micro-chipping and micro-softening effect of MWCNTs validated through the peak to valley interspaces of the worn spot. The micro-chipping of interacting surface may occur in two stages. In the first stage, the nucleation of shear phase volumes at the beginning of unloading then the unstable shear spots are deforms plastically.

\section{CONCLUSIONS}

The Mustard oil used in the study is non-hazardous, cheap and keeps the optics of sustainable development. The Mustard oil as alternative lubricating agent is a promising solution to formulate Environmentally Acceptable Lubricant for the wide range of industrial applications. In this study, the deformation behavior of relatively moving interacting surface (matrix material and Berkovich indenter tip) lubricated by Mustard oil and different weight fractions of MWCNTMustard oil nanofluid through Nanoindentation technique. The results show that the induced subsurface deformation rate of the matrix material is significantly reduced through the nanofluids lubrication in which micro-chipping and microsoftening effect of MWCNT played a vital role. It show that the nanofluids lubrication have significantly contributed in the surface softening effect under stress induced-phase transformations. The dislocation movements along the slip planes cause the micro-chipping and mechanical twinning of surface atoms closer to the Berkovich indenter tip. The $2 \mathrm{wt} \%$ of MWCNT-Mustard oil nanofluid lubricated matrix material exhibits optimum stability and lubricating properties. The benefit of replacing mineral-oil-based lubricants by Mustard oil is expected to be considerable.

\section{REFERENCES}

1. R.D. Kulkarni, P.S. Deshpande, S.U. Mahajana, P.P. Mahulikar, Epoxidation of mustard oil and ring opening with 2-ethylhexanol for biolubricants with enhanced thermo-oxidative and cold flow characteristics, Ind. Crops Prod. 49 (2013) 586-92.

2. Y. Singh, A. Farooq, A. Raza, M.A. Mahmood, S. Jain, Sustainability of a non-edible vegetable oil based bio-lubricant for automotive applications: A review, Process Saf. Environ .111 (2017) 701-713.

3. J.F. Hoffmann, J.F. Henry, G. Vaitilingom, R. Olives, M. Chirtoc, D. Caron, Temperature dependence of thermal conductivity of vegetable oils for use in concentrated solar power plants, measured by 3 omega hot wire method, Int. J. Therm. Sci. 107 (2016) 105-110.

4. M. Ghasemlou, F. Daver, E. P. Ivanova, B. Adhikari, Polyurethanes from seed oil-based polyols: A review of synthesis, mechanical and thermal properties, Ind. Crops Prod. 142 (2019) 111841.

5. Y. Wang, C. Li, Y. Zhang, B. Li, M. Yang, X. Zhang, Comparative evaluation of the lubricating properties of vegetable-oil-based nanofluids between frictional test and grinding experiment, J. Manuf. Proc. 26 (2017) 94-104.

6. S.V. Sujith, A.K. Solanki, R.S. Mulik, Experimental evaluation on rheological behavior of $\mathrm{Al}_{2} \mathrm{O}_{3}$-pure coconut oil nanofluids, J. Mol. Liq. 286 (2019) 110905

7. S.B. Mousavi, S.Z. Heris, M.G. Hosseini, Experimental investigation of $\mathrm{MoS}_{2} /$ diesel oil nanofluid thermophysical and rheological properties, Int. Commun. Heat Mass. 108 (2019) 104298. 
8. S.R. Valantina, K.A. Jayalatha, D.R.P. Angeline, S. Uma, B. Ashvanthe, Synthesis and characterisation of electro-rheological property of novel ecofriendly rice bran oil and nanofluid, J. Mol. Liq. 256 (2018) 256-66.

9. K.M. Kumar, A. Ghosh, Assessment of cooling-lubrication and wettability characteristics of nano-engineered sunflower oil as cutting fluid and its impact on SQCL grinding performance, J. Mater. Process. Tech. 237 (2016) 55-64.

10. S.S. Sanukrishna, S. Vishn, T.S. Prakash, Effect of oxide nanoparticles on the thermal, rheological and tribological behaviours of refrigerant compressor oil: An experimental investigation, Int. J. Refrig. 90 (2017) 32-45.

11. S.U. Ilyas, M. Narahari, J.T.Y, Thenga, R. Pendyala, Experimental evaluation of dispersion behavior, rheology and thermal analysis of functionalized zinc oxide-paraffin oil nanofluids, J. Mol. Liq. 294 (2019) 111613.

12. Y. Mohammadfam, S.Z. Heris, L. Khazini Experimental Investigation of $\mathrm{Fe} 3 \mathrm{O} 4 /$ hydraulic oil magnetic nanofluids rheological properties and performance in the presence of magnetic field, Tribol. Int. 142 (2020) 105995.

13. V. Zin, F. Agresti, S. Barison, L. Litti, L. Fedele, M. Meneghetti, M. Fabrizio Effect of external magnetic field on tribological properties of goethite (aFeOOH) based nanofluids, Tribol. Int. 127 (2018) 341-50.

14. X. Liu, N. Xu, W. Li, M. Zhang, L. Chen, W. Lou, X. Wang, Exploring the effect of nanoparticle size on the tribological properties of $\mathrm{SiO}_{2} /$ polyalkylene glycol nanofluid under different lubrication conditions, Tribol. Int. 109 (2017) 467-72.

15. A.K. Sharma, A.K. Tiwari, A.R. Dixita, Characterization of $\mathrm{TiO}_{2}, \mathrm{Al}_{2} \mathrm{O}_{3}$ and $\mathrm{SiO}_{2}$ Nanoparticle based Cutting Fluids, Mat. Today Proceed. 3(6) (2016) 1890-1898.

16. S.M. Hashemi, M.A.A. Behabadi, An empirical study on heat transfer and pressure drop characteristics of $\mathrm{CuO}$-base oil nanofluid flow in a horizontal helically coiled tube under constant heat flux, Int. Commun. Heat Mass. 39(1) (2012) 144-151.

17. M.J. Babu, N. Sandeep, Effect of nonlinear thermal radiation on non-aligned bio-convective stagnation point flow of a magnetic-nanofluid over a stretching sheet, Alexandria Eng. J. 55(3) (2016) 1931-1939.

18. M. Anish, J. Jayaprabakar, V. Jayaprakash, A. Prabhu, V.B. Ram, M.A. Jijo, Measurement dependent temperature of thermal conductivity and viscosity by using $\mathrm{Al}_{2} \mathrm{O}_{3}$ - Therminol 55 based nanofluid, Mat. Today Proceed. DOI: 10.1016/j.matpr.2019.05.457.

19. M. Hatami, S.M. Rezaei, M. Tahari, D. Jing, Recent developments in magneto-hydrodynamic $\mathrm{Fe}_{3} \mathrm{O}_{4}$ nanofluids for different molecular applications: A review study, J. Mol. Liq. 250 (2018) 244-258.

20. N.N. Esfahani, D. Toghraie, M. Afrand, A new correlation for predicting the thermal conductivity of $\mathrm{ZnO}-\mathrm{Ag}(50 \%-50 \%) /$ water hybrid nanofluid: An experimental study, Powder Technol. 323 (2018) 367-73.

21. B.A.J. Rose, H. Singh, N. Verma, S. Tassou, S. Suresh, N. Anantharaman, Investigations into nanofluids as direct solar radiation collectors, Solar Energy 147 (2017) 426-31.

22. S. Akilu, A.T. Baheta, A.A. Minea, K.V. Sharma, Rheology and thermal conductivity of non-porous silica $\left(\mathrm{SiO}_{2}\right)$ in viscous glycerol and ethylene glycol based nanofluids, , Int. Commun. Heat Mass. 88 (2017) 245-53.

23. M.F. Nabil, W.H. Azmia, K.A. Hamid, R. Mamat, Experimental investigation of heat transfer and friction factor of $\mathrm{TiO}_{2}-\mathrm{SiO}_{2}$ nanofluids in water:ethylene glycol mixture, Int. J. Heat Mass Transf. 12 (2018) 1361-1369

24. N. Yadav, A.K. Jaiswal, K.K. Dey, V.B. Yadav, G. Nath, A.K. Srivastava, R. R. Yadava, Trimetallic Au/Pt/Ag based nanofluid for enhanced antibacterial response, Mat. Chem. Phy. 218 (2018) 10-17.

25. S.S. Chaudhari, R.R. Chakule, P.S. Talmale, Experimental Study of Heat Transfer Characteristics of $\mathrm{Al}_{2} \mathrm{O}_{3}$ and $\mathrm{CuO}$ Nanofluids for Machining Application, Mat. Today Proceed. 18(3) (2019) 788-797.

26. L.T. Benos, E.G. Karvelas, I.E. Sarris, Crucial effect of aggregations in CNTwater nanofluid magnetohydrodynamic natural convection, Therm. Sci. Eng. Progress 11 (2019) 263-271.

27. M.S.B. Reddy, N. Jayarambabu, R.K.K. Reddy, S. Kailasa, K.V. Rao, Study of acoustic and thermodynamic factors of synthesized $\mathrm{ZnO}$-water nanofluid by ultrasonic technique, Mat. Today Proceed. DOI: 10.1016/j.matpr.2019.04.200.

28. M.M. Sarafraz, V. Nikkhah, M. Nakhjavani, A. Arya, Thermal performance of a heat sink microchannel working with biologically produced silver-water nanofluid: Experimental assessment, Exp. Therm. Fluid Sci. 91 (2018) 509519.

29. R. Maheswaran, J. Sunil, Effect of nano sized garnet particles dispersion on the viscous behavior of extreme pressure lubricant oil, J. Mol. Liq. 223 (2016) 643-651.

30. R. Maheswaran, J. Sunil, Relative anti-wear property evaluation of nano garnet gear lubricant, Int. J. Surf. Sci. Eng. 11(4) (2017) 320-343.

31. R. Maheswaran, J. Sunil, R. Vettumperumal, K.K. Sadasivuni, Experimental investigation on the thermal properties of NiO-nanofluids, J. Mol. Liq. 8(7) (2019) $1577-1582$.

32. J. Sunil, J. Vignesh, R. Vettumperumal, R. Maheswaran, R.A.A. Raja, The Thermal Properties of CaO-Nanofluids, Vacuum 161 (2019) 383-388.

33. A. Sajeeb, P.K. Rajendrakumar, Comparative evaluation of lubricant properties of biodegradable blend of coconut and mustard oil, J. Clean. Prod. 240 (2019) 118255.

34. G. Ajithkumar, N.H. Jayadas, M. Bhasi Analysis of the pour point of coconut oil as a lubricant base stock using differential scanning calorimetry, Lubr. Sci. 21(1) (2009) 13-26.

35. F. Aladedunye, R. Przybylski, Frying stability of high oleic sunflower oils as affected by composition of tocopherol isomers and linoleic acid content, Food Chem. 141(3) (2013)2373-2378.

36. R. Kreivaitis, J. Padgurskas, M. Gumbyte, V. Makareviciene, B. Spruogis, The influence of oxidation on tribological properties of rapeseed oil, Transport 26(2) (2011) 121-127.

37. L.I.F. Cabrera, E.A.G. Hernandez, J. Perez-Gonzalez, B.M.M. Santibanez, R. Lewis, Effects of jatropha lubricant thermooxidation on the tribological behaviour of engine cylinder liners as measured by a reciprocating friction test, Wear. 426-427 (2019b) 910-918.

38. S. Rani, M.L, Joy, K.P. Nair, Evaluation of physiochemical and tribological properties of rice bran oilebiodegradable and potential base stoke for industrial lubricants, Ind. Crops Prod. 65 (2015) 328-333.

39. A. Aravind, M.L. Joy, K.P. Nair, Lubricant properties of biodegradable rubber tree seed (Hevea brasiliensis Muell. Arg) oil, Ind. Crops Prod. 74 (2015) 14-19.

40. J.K. Mannekote, S.V. Kailas The effect of oxidation on the tribological performance of few vegetable oils, J. Mater. Res. Technol. 1(2) (2012) 9195.

41. M.H. Mosarof, M.A. Kalam, H.H. Masjuki, A. Arslan, I.M. Monirul, A.M. Ruhul, Analysis of thermal stability and lubrication characteristics of Millettia pinnata oil, RSC Adv. 6(84) (2016) 81414-81425.

42. N.H. Jayadas, K.P. Nair, Study of the anti-wear properties of coconut oil using quantum chemical calculations and tribological tests, J. Tribol. 128 (2006) 654-659.

43. E.E.G. Rojas, J.S.R. Coimbra, J.T. Romero, Thermophysical Properties of Cotton, Canola, Sunflower and Soybean Oils as a Function of Temperature, Int. J. Food Prop.16(7) (2013) 1620-1629.

44. A, Sajeeb, P.K. Rajendrakumar, Comparative evaluation of lubricant properties of biodegradable blend of coconut and mustard oil, J. Clean. Prod. 240 (2019) 118255.

45. S.B. Naghadeh, S. Vahdatifar, Y. Mortazavi, A. Khodadadi, A. Abbasi, Functionalized MWCNTs effects on dramatic enhancement of $\mathrm{MWCNTs} / \mathrm{SnO}_{2}$ nanocomposite gas sensing properties at low temperatures, Sensor. Actuat. B-Chem. 223 (2016) 252-260

46. A. Miranda, N. Barekar, B.J. McKay, MWCNTs and their use in Al-MMCs for ultra-high thermal conductivity applications: A review, J. Alloy. Compound. 774 (2019) 820-40.

47. N. Forintos, T. Czigany, Multifunctional application of carbon fiber reinforced polymer composites: Electrical properties of the reinforcing carbon fibers - A short review, Compos. B: Eng. 162 (2019) 331-343.

48. C. Zeng, C. Lin, J. Zhang, J. Liu, G. He, Y. Li, Yang Grafting hyperbranched polyester on the energetic crystals: Enhanced mechanical properties in highly-loaded polymer based composites, Compos. Sci. Technol. 184 (2019) 107842.

49. Y. Liad, Q, Wang, S. Wang, A review on enhancement of mechanical and tribological properties of polymer composites reinforced by carbon nanotubes and graphene sheet: Molecular dynamics simulations, Compos. Part B: Eng. 160 (2019) 348-361. 
50. J. Meng, X. Li, C. Wang, H. Guo, J. Liu, H. Xu, Carbon nanotubes activate macrophages into a M1/M2 mixed status: recruiting naive macrophages and supporting angiogenesis, ACS Appl. Mat. Interfac. 7 (2015) 3180-3188.

51. K.K. Gangu, S. Maddilaa, S.B. Mukkamala, S.B. Jonnalagadda, Characteristics of MOF, MWCNT and graphene containing materials for hydrogen storage: A review, J. Energy Chem. 30 (2019) 132-144.

52. J. Huang, S. Her, X.X. Yang, M. Zhi, Synthesis and Characterization of Multi-Walled Carbon Nanotube/Graphene Nanoplatelet Hybrid Film for Flexible Strain Sensors, Nanomaterial. 8 (2018) 786.

53. A. Sengupta, N K. Gupta, MWCNTs based sorbents for nuclear waste management: A review, J. Environ. Chem. Eng. 5(5) (2017) 5099-5114.

54. J. Xiao, W. Li, Z. Sun, D.A. Lange, S.P. Shah, Properties of interfacial transition zones in recycled aggregate concrete tested by nanoindentation, Cement. Concrete Comp. 37 (2013) 276-292.
55. H. Huang, J. Yan, Possibility for rapid generation of high-pressure phases in single-crystal silicon by fast nanoindentation, Semicond. Sci. Technol. 30 (2015) 115001.

56. J. Chen, L. Tan, X. Yu, I. P. Etim, M. Ibrahim, K. Yang, Mechanical properties of magnesium alloys for medical application: A review, J. Mech. Behav. Biomed. 87 (2018) 68-79.

57. P. Khatri, S. Jain, S. Pandey, A cradle-to-gate assessment of environmental impacts for production of mustard oil using life cycle assessment approach, J. Clean. Prod. 166 (2017) 988-997.

58. M.A. Reddy, S. Ramaprabhu, Hydrogen adsorption properties of singlewalled carbon nanotube-Nanocrystalline platinum composites, Int. J. Hydrog. Energy. 33 (2008) 1028-1034.

59. P. Scherrer, Determination of the size and the internal structure of colloid particles by means of X-ray beams, News from the Society of Sciences, Gottingen, Math.-Phy. Cl 2 (1918) 98-100. 